American Journal of Economics and Business Administration 2 (1): 6-11, 2010

ISSN 1945-5488

(C) 2010 Science Publications

\title{
The Malaysian Public Procurement's Prevalent System and its Weaknesses
}

\author{
${ }^{1}$ Rohana Othman, ${ }^{2}$ Husein Zakaria, ${ }^{3}$ Norlaili Nordin, ${ }^{4}$ Zamzam Shahidan and ${ }^{5}$ Kamaruzaman Jusoff \\ ${ }^{1}$ Faculty of Accountancy, University Technology MARA, 40500 Shah Alam, Selangor, Malaysia \\ ${ }^{2}$ Department of Banking Supervision, Bank Negara Malaysia, 50929 Kuala Lumpur, Malaysia \\ ${ }^{3}$ Department of Risk Management, Investigation Division, Inland Revenue Board, \\ 50758 Kuala Lumpur, Malaysia \\ ${ }^{4}$ Finance and Procurement Division, Royal Malaysian Customs, 01000 Kangar, Perlis, Malaysia \\ ${ }^{5}$ Faculty of Forestry, University Putra Malaysia, Serdang 43400, Selangor, Malaysia
}

\begin{abstract}
Problem statement: This study examined the public procurement system as prevalent in the Malaysian government system of administration. Various aspects of public procurement are outlined including types and the processes that entail public procurement. This study also highlighted the weaknesses in the manual public procurement processes that are opened to potential abuse and mismanagement resulting in corruption. This study places the Malaysian Government public procurement system under the spotlight zeroing on allegations of abuse, tampering and corrupt practices. The study concluded that the large amount of funds allocated to public procurement coupled with excessive human intervention opportunities opened avenues that increase the risk of system abuse, profiteering and corruption. Case studies on the abuse and corruption of the public procurement system highlight the need for the Malaysian Government to eliminate the loopholes in the system, arrest the rot and implement a transparent, efficient and accountable public procurement system. Approach: Documents from the Ministry of Finance on public procurement including, among others, the Procurement Guideline Book, The Financial Procedures Act 1957, the Treasury Instructions (TI) and the Treasury Circular Letter (TCL) were scrutinized in studying the Malaysian Government public procurement system, its various attributes, types and processes that reflect a diversified approach to public procurement. Three case studies were cited to illustrate the susceptibility of the system to abuse and corruption. Results: Despite claims of openness and transparency of the public procurement system, it was found the current system is replete with the risk of abuse, unethical manipulations and corrupt practices. This research is limited to the analysis of data and processes related to the Malaysian Government public procurement system. The sensitivity of the subject may inhibit the collection of empirical data via surveys or interviews. Records of court cases involving corruption offered clues to areas in the system prone to human intervention. Conclusion: This research helps identify areas of improvement in the Malaysian Government public procurement system and thus raises the possibility of enormous cost savings and the eradication of rampant corruption and abuse. This study shows that, while the public procurement system may be available in the Malaysian Government system of administration, weaknesses in the public procurement processes may open avenues for corruption to take place. Corruption stemming from a procurement system weak on aspects of 'check and balance' will cause a major drain on the national budget and can result in a huge loss of public funds. Eventually, the nations credibility in the eyes of the international business community will be severely tainted thus reducing the overall competitiveness of the country.
\end{abstract}

Key words: Procurement, Public procurement, public procurement processes, risks in public procurement

\section{INTRODUCTION}

In general terms, public procurement referred to purchases of goods and services from suppliers on behalf of the government, which was represented by the various municipalities, provinces, states, national offices and also the federal offices. In Malaysia, the Ministry Of Finance (MOF) was responsible for all the procurement procedures, both internally and outside of Malaysia. Guidelines had been published by the MOF

Corresponding Author: Kamaruzaman Jusoff, Faculty of Forestry, University Putra Malaysia, Serdang 43400, Selangor, Malaysia 
Am. J. of Economics and Business Administration 2 (1): 6-11, 2010

that acted as the legal framework for public procurement. Among them included the Procurement Guideline Book, The Financial Procedures Act 1957, the Treasury Instructions (TI) and the Treasury Circular Letter (TCL). All of these identified the types of procurement and the processes involved as the MOF's function was primarily in the areas of controlling, enforcement, supervision, reconciliation, usage, distribution and storage of procurement for government departments.

Examples of the information exhibited included; the range of purchases for products such as small items, viz., office stationeries to office equipment and even extended to huge assets such as vehicles, machineries and the most non-liquid asset, land and building. These guidelines also covered the provisions for the purchase of services. Examples of services purchased on behalf of the government included those received from consultants and advisors in the areas of engineering, technical, financial, legal and others.

Table 1 indicates the amount of the annual budget that had been allocated for procurement by the Malaysian Government.

Types of public procurement: In specific terms, public procurement fell into 4 categories, viz.

Tender: This category was specifically for all public procurements which had a value above RM200,000. Tenders would be invited from suppliers for one item or a class of item that was approved by the Treasury Secretary General or the State Treasury.

Open tender: Open tender involved all tenders received from contractors who were registered with MOF notably for products and services, coupled with those contractors who were listed under the Construction Industry Development Board (CIDB) Malaysia and contractor service centre.

Some of the classes under the open tender category included:

- Limited for Bumiputera contractors only

- Open tender based on a pre-qualification which was for the purpose of selection of contractors who were approved by the treasury and who had the required experience, technical capability and financial stability to carry out the project

- Limited tender was for products and services that did not exceed RM5 million and had the approval from the Procurement Board of that particular agency. All tenders that exceeded RM5 million must get the approval from the treasury
Table 1: Malaysian government budget on procurement from 1999 till 2006

\begin{tabular}{llll}
\hline Year & $\begin{array}{l}\text { Total government } \\
\text { budget (RM million) }\end{array}$ & $\begin{array}{l}\text { Percentage for } \\
\text { procurement }\end{array}$ & $\begin{array}{l}\text { Total allocation } \\
\text { (RM million) }\end{array}$ \\
\hline 2006 & 134,748 & 15.9 & 21,425 \\
2005 & 117,445 & 16.0 & 18,791 \\
2004 & 109,990 & 15.6 & 17,158 \\
2003 & 71,737 & 19.9 & 14,253 \\
2002 & 66,706 & 17.8 & 11,854 \\
2001 & 63,757 & 16.8 & 10,703 \\
2000 & 56,547 & 13.0 & 7,360 \\
1999 & 46,699 & 13.0 & 6,074 \\
\hline
\end{tabular}

Source: www.mof.gov.my

- Direct negotiation referred to the procurement process with potential contractors who were used for exceptional circumstances, such as projects that needed specific expertise and they possessed extremely high financial stability

Quotations: The third category for public procurement of good and services revolved around the specific quotations required as detailed below:

- For purchases ranging from RM50,000-200,000, the department needed to get quotations from at least (5) suppliers who were registered with MOF for the specific code of items being sourced

- If the amount of the purchase fell between RM50,000-100,000, then the quotations must be received from at least 5 suppliers with Bumiputera status and also registered with MOF for the specific code of items.

- Quotations were also required for work procurement. This referred to the costs involved for repair work that did not change the original structure of the building. These costs should fall into the range of RM20,000 and 100,000. These would be based on the Civil Engineering Standard Method of Measurement (CESMM). The contractor must be chosen by rotation or voting from the 'Class F' contractors in the district or the nearest district for such a project. The project also needed to be registered with the Contractor Service Centre for that specific class

- However for any work on repairs, maintenance or renovation that required changes to either the original structure, electrical or mechanical settings, must be first referred to the Technical Department of the Treasury for their approval before quotations were obtained

Direct purchase: The fourth category of public procurements involved the purchase of goods and services of up to a value of RM50,000. Heads of 
Am. J. of Economics and Business Administration 2 (1): 6-11, 2010

Departments were allowed to source procurement from any company that was known to offer reasonable prices. For products or services procurement between the range of RM10,000-50,000 a year for any item or class of item, the respective government agency was allowed to purchase directly from any Bumiputera supplier who was registered for that particular class.

Procurement processes: Having an understanding of the categories of public procurement helped to relate to the processes involved in the actual procurement of goods and services. These involved a series of procedures and complex processes which were bound by rules and regulations. The processes were carried out by the public officials who represented the public authority or the government department that gave the approval for the suppliers. The complete process required a long chain of internal authorizations and scrutiny, several visits by suppliers to the government departments and the generation of tons of paper-based statements and evaluations. Some of the processes included the steps detailed below:

- Preparing and deciding on what to buy

- Determining the quantity and costing

- Selecting the supplier

- Assessing the supplier's past performance

- Preparing the contract agreement

- Monitoring the services or completion as per agreement

- Ensuring that the goods are received on time, in good condition and meets the standard of quality as stated in the contract

Figure 1 outlined the flowchart for public procurement. It showed the parties and work procedures involved in making the procurement. There were at least 6 parties involved in completing the process as shown in Fig. 1.

Weaknesses of the public procurement processes: Since large amounts of public funds were expended to purchase goods and services from the private sector and most of the procedures were conducted manually, two major risks became imminent. These were the risk of human error, which was exceptionally high considering the numerous processes and movement of documents that stretched over a long time frame and an equally potent risk of corruption during the stages of the procurement process.

Risks: To attain a clearer appreciation of the risks embedded in the public procurement processes, a study was conducted by Organization for Economic Co- operation and Development (OECD) Public Governance Committee. Their survey focused on the practices of the procurement officers. It was revealed that at each stage of the public procurement process, particular risks emerged, such as:

\section{Stage 1 risks:}

- Inadequate choices of procedures

- Lack of adequate assessment and planning

- Insufficient timeframe preparation

- Inconsistent practices across the bidders in first stage

\section{Stage 2 risks:}

- The selection of suppliers had inconsistent bidders' information

- Conflict of interest situations were prevalent

- Lack of access to record procedures

- Biased towards favored bidders

- Collusive bidding resulting in incorrect prices

\section{Stage 3 risks:}

- Contract administration had insufficient monitoring process

- No transparency in contracts being awarded

- Lack of work or goods verification

- Lack of separation of financial duties especially involving the payment process. Among the three stages of risks, the most potent stage was stage 2, where the selection process led to the award of a procurement contract to a supplier. At this stage, the criterion for the supplier selection was not based on the lowest price offered, rather on the credibility of the supplier to deliver the right goods or services. It was where the transparency in selection process became questionable, notably when the valuation criterion was not clearly stated and there was no justification for it. Most of the time, it depended heavily on the judgment made by the approving authority. Due to the human judgment factor which proved to be highly subjective, the officers tended to manipulate and made biased assessment which ultimately led to cases of corruption

Additionally, the Transparency International Authority conferred that the other two stages, viz., Stage 1 and 3 were also becoming "increasingly exposed to corruption". The United Nations (2004) article 9 (2) provided that a procurement system should ensure adequate internal control and risk management. 
Am. J. of Economics and Business Administration 2 (1): 6-11, 2010

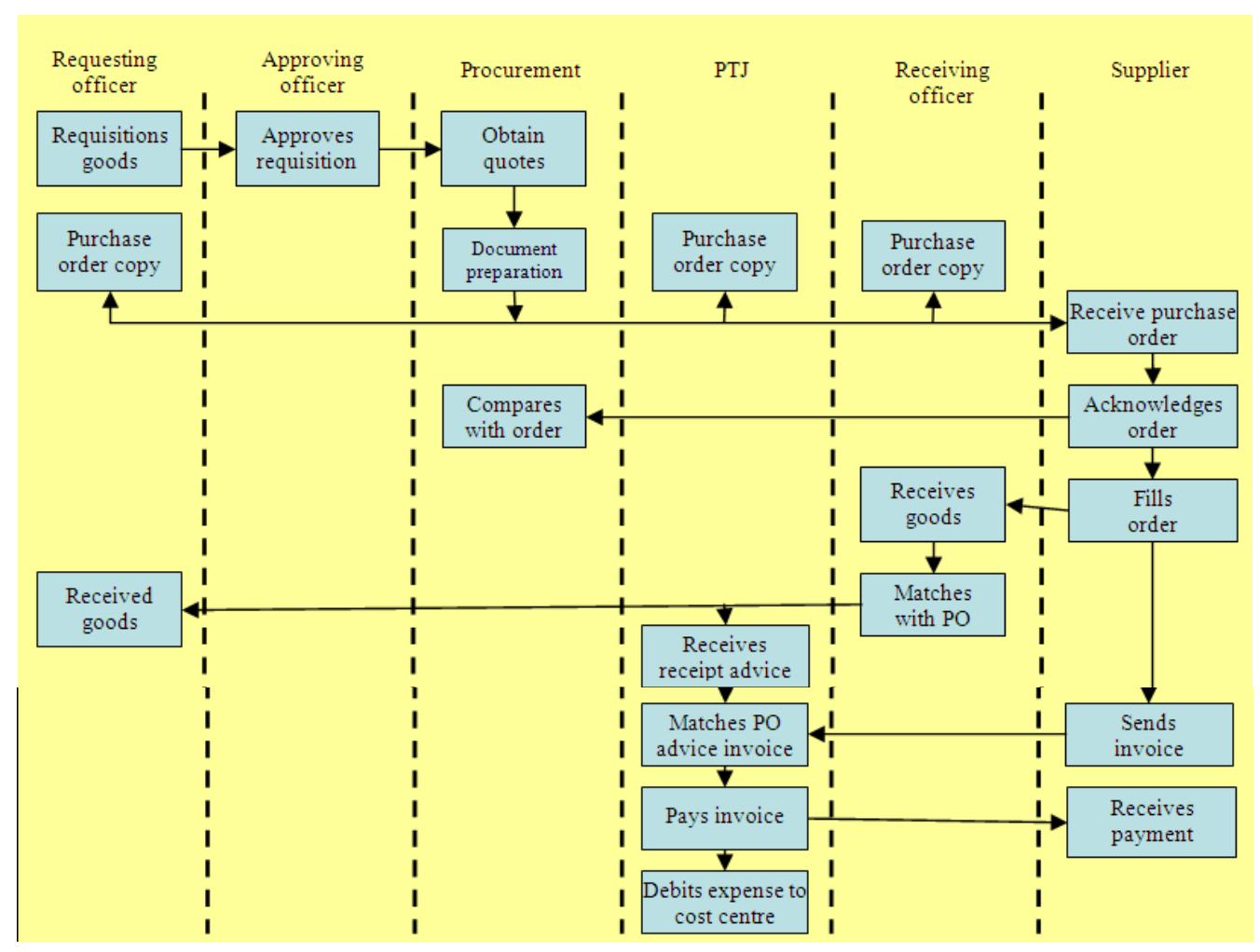

Fig. 1: Public procurement flowchart; Note: PTJ stands for responsibility centre

Thus the procurement system should have installed an arrangement of integrated systems that linked the various functions such as budgeting and planning, procurement procedures and the contract or project implementation processes.

Corruption in public procurement: Although several definitions of corruption were found in the literature, it was commonly referred to as being the exploitation of public power for private benefit (Theis and Stevens, 2007) Public procurement had been identified as the government activity most vulnerable to corruption, collusion, fraud and manipulation (United Nations, 2004).

The types of corruption schemes prevalent could be classified under 5 main streams, namely;

Kickbacks: Kickbacks were defined by Utstein AntiCorruption Resource Centre (2008) as the method where illegal secret payments were made as a return for a favor or a bribe and were usually calculated in the form of a percentage, a share, a cut, a commission or a payoff. Kramer (2008) in his column 'Corruption and Fraud: 'The Basics' stated that there were a set of red flags for these kickbacks. These included the following:
- Bias in contractor selection

- Preferential treatment for certain contractors

- Contractors were allowed to quote higher prices

- Government agency was allowed unnecessary purchases

- Government officials lived beyond their means

- Frequent use of the same contractors

- Receiving of regular gifts from contractors

Bid rigging: Bid rigging happened when bidders colluded with one another and kept the bid amount at a pre-determined level. This usually occurred in a competitive public tender environment (Ware et al., 2007). This intentional manipulation as done by the members of the bidding group who submitted common bids, discouraged a price war (Organization of Economic Co-operation and Development, 2007). The interested bidders would agree in advance the following details; who would submit competitive bids, at what prices, who would win and how the profits would be shared among the bidders. Sometimes, this process would involve public officials, who were responsible for conducting the tender and who were willing to collaborate with the bidders in the bid-rigging fraud.

Some of the common red flags of bid-rigging according to Ware et al. (2007) were: 
- Different bidders submitting similar bidding value

- The winning bidder delegating or sub-contracting part of the contract to the losing bidders

- Evidence of physical alteration of more than one bid

- Same handwriting and information content found in the tender documents

- Apparent connections between bidders (e.g., common addresses or phone numbers)

- Similarities between specifications among the bidders' and the winning contractor's product or services

Using 'front' or 'shell companies': Another common form of corruption among the public officials was to form a shell company. The shell company was an entity created by an employee usually in the name of a spouse, a close relative, a friend or even using a fictitious name, with the intention to commit fraud (Ware et al., 2007). Often the shell company proved to be nothing more than a fabricated name and a post office box or mail drop address that an employee used to collect the fruits of the fraud. Using the shell companies, the corrupt public officials could 'fix' the tender processes and put artificial pressure on the other bidders in order to ensure that their company would secure the contract being awarded and benefit from it.

The major red flags of these shell companies were:

- The location at which the subcontractor's company was registered for example the Cayman Islands

- Payment to vendors not on the approved vendor list

- Vendors not listed in the business or telephone directories

- Invoicing of goods or services that cannot be located or verified

- Vendors' address are only a mail drop one

Excess payments made to legitimate vendors: The fourth type of corruption scheme could occur when dishonest vendors do the following; either they submit multiple bills on different contracts or on work orders for work performed, or even though the expense was incurred only once they intentionally submit false bills (meaning that no services were provided), or they submit duplicate or inflated invoices.

A fraudulent public official could collude in this scheme and share in the profits by writing similar work orders under different contracts and accepting the multiple billings. Thus, this would create unnecessary surplus claims to the vendors involved, known as 'excess payments'.
Some of the major red flags related to this scheme were:

- Vendor submission of several billings for the same or similar expenses or work under different jobs or contracts

- Vendor submission of the same or similar documentation to support billings on different contracts

- Multiple awarding of projects for similar work given to the same vendor

- Similar work orders being issued to the same vendor under more than one contract

- Weak or un-enforced controls in the receipt of goods and payment of invoices

- Inadequate or copied or apparently altered supporting documents

Misrepresentation of facts: The fifth type of corruption scheme referred to the bidder or vendor who lied about their previous contracts secured or made an exaggeration of their previous experience in order to secure the contract from the government. In this case, the public officials conspired with the selected bidder to enable the bidder to earn a contract which in actual fact the bidder would not have won if the rules of the tender had not been modified to the bidder's advantage.

Examples of red flags related to this scheme were:

- The absence of minutes of the meeting for the process of bid opening by the procuring public official

- Minutes of the meeting were not verified in the original bidding form by the relevant authorized committee members and/or by the respective bidders who participated in the bidding process

- Excessive number of corrections, such as alterations, amendments and modifications in the bidding form submitted

- No stringent follow-up by the public procurement officials to ensure that all the information on the documents submitted were authentic and accurate

Case studies of corruption in public procurement in Malaysia: Three real case studies were highlighted to provide an insight on the fraudulent public procurement practices in Malaysia.

Case 1: Ministry of youth and sports (industrial training institute). 


\section{Type of corruption:}

Unreasonable price: According to the procurement contract, the contractor was to supply certain tools for the specific programs conducted at the training institute. However, the auditor found that there was a significant difference in price quoted in the supplier's contracts and also when compared with the prices of the same tools that were being supplied by different suppliers to the same institution. In this case, exorbitant prices were charged for 5 tools, viz., the Philips Screwdriver, Digital Cameras, plastic cases, 6 seated settees and the 2 Tone Jack (Laporan Ketua Audit Negara, 2006).

\section{Case 2: Alor Gajah municipal council:}

\section{Type of corruption:}

Falsified documentation: The Anti-Corruption Agency (ACA) had arrested an engineer with the Alor Gajah Municipal Council and a contractor for alleged graft involving RM47,100 (The Star, 2008). The contractor was arrested for allegedly providing false information when making his claim for the construction of a retaining wall in Taman Kelemak Jaya. The 37 year-old engineer was arrested as he was alleged to have abetted the contractor. The ACA in a statement said the contractor had submitted a claim for RM88,100 as the cost of constructing the retaining wall when in fact the cost was only about RM41,000. Both were being investigated under Section 11 (c) of the AntiCorruption Act 1997 and have been released on bail.

\section{Case 3: Giat MARA centre:} Type of corruption:

Abuse of position held: A 37 year-old lecturer at the Giat Mara centre here was arrested yesterday morning by the Anti-Corruption Agency (ACA) after he was alleged to have awarded his wife's company a tender. The man was said to have abused his position as a quotation analysis officer by taking part in a contractor/supplier/wholesaler central committee meeting for awarding of the tender (The New Straits Times, 2008).

\section{CONCLUSION}

Public procurement involved large amounts of public money that made procurement highly vulnerable to corruption. In the article entitled "Making Government Procurement Transparent" it was noted that government procurement affected the efficiency of public spending due to the huge loss of public funds via fraudulent activities every year. This was also published in the OECD Observer article entitled "Public procurement: Spotting the bribe" which suggested that corruption in public procurement was a growing concern globally (Couthard and Castleman, 2001) and Malaysia was not an exception. As such, the Malaysian government needed to take the appropriate action to overcome the numerous loop-holes in the public procurement activities to ensure a more transparent and efficient system.

\section{REFERENCES}

Couthard, D. and T. Castleman, 2001. Electronic procurement in government: More complicated Than just good business. Proceeding of the 9th European Conference on Information Systems, June 27-29, Bled, Slovinia, pp: 999-1009. (http://is2.1se.ac.uk/asp/aspecis/20010025.pdf

Kramer, W.M., 2008. Corruption and fraud: The Basics-contract and procurement fraud schemes and red flags. http://www.wmkramer.com

Laporan Ketua Audit Negara, 2006. Money for poor used on MBs' homes, ntv7 crew. http://www.mesra.net/forum/lofiversion/index.php/ t57717.html

Organization of Economic Co-operation and Development, (OECD), 2007. Bribery in Public Procurement: Methods, Actors and CounterMeasures. OECD Publishing, Paris, pp: 104.

The New Straits Times, (NST), 2008. Online, Lecturer held in graft case.

The Star, 2008. ACA nabs contractor and engineer.

Theis, D. and B. Stevens, 2007. New report shows strong action in World Bank's global anticorruption fight.

Utstein Anti-Corruption Resource Centre, (UACRC), 2008. Corruption glossary. http://www.u4.no/document/faqs5.cfm\#kickbacks

United Nations, 2004. United Nations Convention against Corruption (UNCAC). http://www.unodc.org/documents/treaties/UNCAC/ Publications/Convention/08-50026_E.pdf

Ware, G., S. Moss, E. Campos and G. Noone, 2007. Corruption in Public Procurement: A Perennial Challenge. In: The Many Faces of Corruption: Tracking Vulnerabilities at the Sector Level, Campos, E. and S. Pradhan (Eds.). The World Bank, ISBN: 0-8213-6725-0, pp: 295-334. 